\title{
Determination of Simultaneous Irbesartan and Hydrochlorothiazide by Ultraviolet Spectrophotometry with Dual Wavelength Method
}

\section{Syahputra Hafid, Muchlisyam Masfria}

Department of Pharmaceutical Chemistry, Faculty of Pharmacy, University of Sumatera Utara, Medan, Indonesia

\begin{abstract}
A B S T R A C T
Objective: The present study was aimed to develop a spectrophotometric method by dual wavelength method in simultaneous analysis of irbesartan and hydrochlorothiazide on tablet preparations without separation. Irbesartan and hydrochlorothiazide are a group of anti-hypertensive drugs that are very effective and safe to use to reduce blood pressure and edema. These drugs often given in combination with these active ingredients can cause problems in quantitative analysis for the quality control of preparations.

Methods: The study was carried out experimentally with a spectrophotometric method, one of which was dual wavelength method and then tested its validity based on validation parameters, namely linearity, accuracy, precision, LOD and LOQ and intraday and interday. Then, this method of irbesartan and hydrochlorothiazide in tablet preparations.

Results: The results of the study were showed that the application of dual wavelength method on the concentration was carried out at $\lambda 263.4 \mathrm{~nm}$ and $281 \mathrm{~nm}$ for irbesartan and at $\lambda 243.4 \mathrm{~nm}$ and $247.6 \mathrm{~nm}$ for hydrochlorothiazide. The results obtained by irbesartan and hydrochlorothiazide on tablets were $(108.04 \pm 2.696)$ and $(94.28 \pm 4.48) \%$ respectively, and with good precision and accuracy.

Conclusions: The ultraviolet spectrophotometry method is dual wavelength method successfully applied for the determination of the concentration of irbesartan and hydrochlorothiazide in tablets.
\end{abstract}

Keywords: Irbesartan, hydrochlorothiazide, tablets, ultraviolet spectrophotometry and dual wavelength method

\section{A R T I C L E I N F 0: Received 15 April 2019; Review Completed 25 May 2019; Accepted 30 May 2019; Available online 15 June 2019

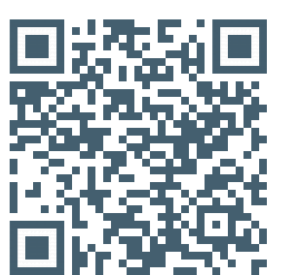 \\ Cite this article as: \\ Syahputra Hafid, Muchlisyam Masfria, Determination of Simultaneous Irbesartan and Hydrochlorothiazide by Ultraviolet Spectrophotometry with Dual Wavelength Method, Asian Journal of Pharmaceutical Research and Development. 2019; 7(3):01-04, DOI: http://dx.doi.org/10.22270/ajprd.v7i3.512 \\ *Address for Correspondence: \\ Hafid Syahputra, Department of Pharmaceutical Chemistry, Faculty of Pharmacy, University of Sumatera Utara, Medan, 20155, Indonesia}

\section{INTRODUCTION}

$\mathrm{T}$ The combination of Irbesartan (IRB) and Hydrochlorothiazide (HCT) is very effective and safe to use to reduce blood pressure and edema accompanied by complications and minimal side effects, namely hyperkalemia. Irbesartan has the chemical name 2-Butyl-3 - [[20- (1H-tetrazol-5-yl) [1, 10-biphenyl] -4-yl] methyl] 1, 3-diazaspiro [4.4] non-1- id -4-one and hydrochlorothiazide (HCT) chemical name 6-Chloro-3, 4dihydro-2H-1，2，4-benzothiadiazine-7-sulfonamide 1,1 dioxide. Determination of IRB and HCT in one condition was determined by the spectrophotometric method, where the IRB had a maximum absorbance at $246 \mathrm{~nm}$ and 274 for $\mathrm{HCT}^{1-2}$.
Spectrophotometry is a simple, fast and relatively easier method compared to other methods, dual wavelength method (DWM) is one of the spectrophotometric methods that can be used to analyze two drug mixtures simultaneously without having to do the separation, easily applied to routine analysis and without need derivatization first ${ }^{3-4}$.Dual wavelength method, in this method two wavelengths are chosen $(\lambda 1, \lambda 2)$ where drug A shows the same absorbance (or the difference between absorbance is zero) so drug B can be determined and vice versa for drug $\mathrm{B}^{5}$. This method can be an option in determining the level of the drug, it is necessary to do research with the aim to prove the Dual wavelength method can be used to 
determine the levels of IRB and HCT in tablet dosage forms.

\section{MATERIAL AND METHODS}

\section{Material}

Pharmaceutical grades of IRB were from the National Agency of Drug and Food Control of Republic of Indonesia; HCT was from PT Kimia Farma. Tablet C (PT. Sanofi) contained $300 \mathrm{mg}$ IRB and $12.5 \mathrm{mg}$ HCT. All other chemicals and reagents used were for analytical grade.

\section{Apparatus and conditions}

UV-Visible Spectrophotometer (Shimadzu 1800) with a computer equipped with UV probe 2.43 software (UV1800 Shimadzu), the absorption was recorded at a wavelength of 200-400nm using a $1 \mathrm{~cm}$ cuvette using UVprobe software. Analytical balance (sartorius), sonicator (Branson 1510) glass tools, mortal and other tool required in sample preparation.

\section{Preparation of standard stock solution}

The IRB and HCT (50 mg respectively) were moved into a $50 \mathrm{~mL}$ volumetric flask and then were dissolved with 0.1 $\mathrm{N} \mathrm{NaOH}$ and added it to the mark line. The standard stock concentration was $1000 \mu \mathrm{g} / \mathrm{mL}$ (stock solution I). The 5 $\mathrm{mL}$ of parent solution was transferred into a $50 \mathrm{~mL}$ volumetric flask and then was diluted with $0.1 \mathrm{~N} \mathrm{NaOH}$ by adding it to the mark line, and the concentration has become $100 \mu \mathrm{g} / \mathrm{mL}$.

\section{Determination of Absorption Maximum Spectrum and Spectrum absorption ratio}

The IRB (10mL) and HCT $(8 \mathrm{~mL})$ were pipetted from (stock solution II) and transferred into a $25 \mathrm{~mL}$ volumetric flask respectively. Next, the solution is diluted with $0.1 \mathrm{~N}$ $\mathrm{NaOH}$, then homogeneous so that the concentration is 10 $\mu \mathrm{g} / \mathrm{mL}$ for IRB, $8 \mu \mathrm{g} / \mathrm{mL}$ for HCT and the mixture of the two drugs is the same with the same concentration. The absorption spectrum of the IRB ratio was in the range of $5-15 \mu \mathrm{g} / \mathrm{mL}$ (series A) and $4-12 \mu \mathrm{g} / \mathrm{mL}$ for HCT (series B) and the mixture of both the drugs (series C) in same concentration range were prepared for dual wavelength method.

\section{Procedure Dual Wavelength Method}

The spectrum of IRB show identical absorbance at 243.4 $\mathrm{nm}\left(\lambda_{3}\right)$ and $247.6 \mathrm{~nm}\left(\lambda_{4}\right)$ therefore these two wavelengths were selected for the analysis of HCT. All the solutions of series $\mathrm{A}$ were scanned to ensure that the difference between $\lambda_{3}$ and $\lambda_{4}$ is zero. Similarly, the HCT solutions were scanned to determine the two wavelengths, where absorbance is the same. These two wavelengths were found to be $263.4 \mathrm{~nm}\left(\lambda_{1}\right)$ and $281 \mathrm{~nm}\left(\lambda_{2}\right)$ make were selected for the analysis of IRB. All the solutions of series $\mathrm{B}$ were scanned to ensure that difference between $\left(\lambda_{1}\right)$ and $\left(\lambda_{2}\right)$ is zero. Thereafter, the solution of series $C$ were scanned to ensure that varying concentration of IRB and HCT are not affecting the absorbance at a selected wavelength. The difference in absorbance between $\left(\lambda_{1}\right)$ and $\left(\lambda_{2}\right)$ of series $C$ solution used for the preparation of calibration curve for IRB. Similarly, difference in absorbance between $\lambda_{3}$ and $\lambda_{4}$ of mixed standard solutions was used for the preparation of calibration curve for $\mathrm{HCT}^{6}$.

\section{Validation test}

\section{Linearity}

The solution standard for IRB and HCT for absorption spectrum were made from the selected wavelength points of $263.4 \mathrm{~nm}$ and $281 \mathrm{~nm}$ for IRB, while the HCT were used wavelength of $243.4 \mathrm{~nm}$ and $247.6 \mathrm{~nm}$. The difference in absorbance values from series $\mathrm{C}$ was used to obtain a regression equation for each component at the selected wavelength ${ }^{7-8}$.

\section{Precision of the method}

Reparability of the methods were studied by repeating the methods six times. To study intra-day precision, the method was repeated three times in a day. Similarly, the method was repeated on three different days to determine inter-day precision.

The determination of precision was based on the relative standard deviation (RSD) value $2 \%^{7-8}$.

\section{Recovery test}

Recovery test was calculated by measured recovery percentage in three specific points which were: $80 \%$, $100 \%$, and $120 \%$. In each of the specific points, the test was used $70 \%$ from the sample and $30 \%$ from the pure active substances (standard addition method) ${ }^{7-8}$.

\section{Preparation of sample solution}

Twenty tablets were weighed and crushed homogeneous. Furthermore, weighed amount of powder equivalent to $300 \mathrm{mg}$ of IRB and $12.5 \mathrm{mg}$ of HCT then the equivalence contained there is calculated and weighed up to six repetitions. Subsequently, the powder was incorporated into the flask $50 \mathrm{~mL}$ and was diluted with $0.1 \mathrm{~N} \mathrm{NaOH}$ (with sonicator for 15 minutes). Thereafter, the solution was added with $0.1 \mathrm{~N} \mathrm{NaOH}$ to the mark line and was shaked until homogeneous. Afterwards, the solution was filtered, then was discarded approximately $10 \mathrm{~mL}$ of the first filtrate. Next, $0.5 \mathrm{~mL}$ of filtrate was putted into a 25 $\mathrm{mL}$ flask and was diluted with $0.1 \mathrm{~N} \mathrm{NaOH}$ until the mark line to obtained solution for IRB and HCT concentration of $10 \mu \mathrm{g} / \mathrm{mL}$ and $8 \mu \mathrm{g} / \mathrm{mL}$, respectively. Thereafter, the absorption of solution was measured at a wavelength of 200-400 nm.

\section{RESULT AND DISCUSSION}

\section{Study of overlain spectra and selection of wavelength}

In a study of overlain with the right concentration and in accordance with the law of lambert-beer. With the concentration of the measured solution, $10 \mu \mathrm{g} / \mathrm{mL}$ and $8 \mu \mathrm{g}$ $/ \mathrm{m}$ and the mixture of both in the same concentration, scanned each with a range of 200-400nm and the spectrum of overlain observed from the IRB and HCT is shown in figure 1 


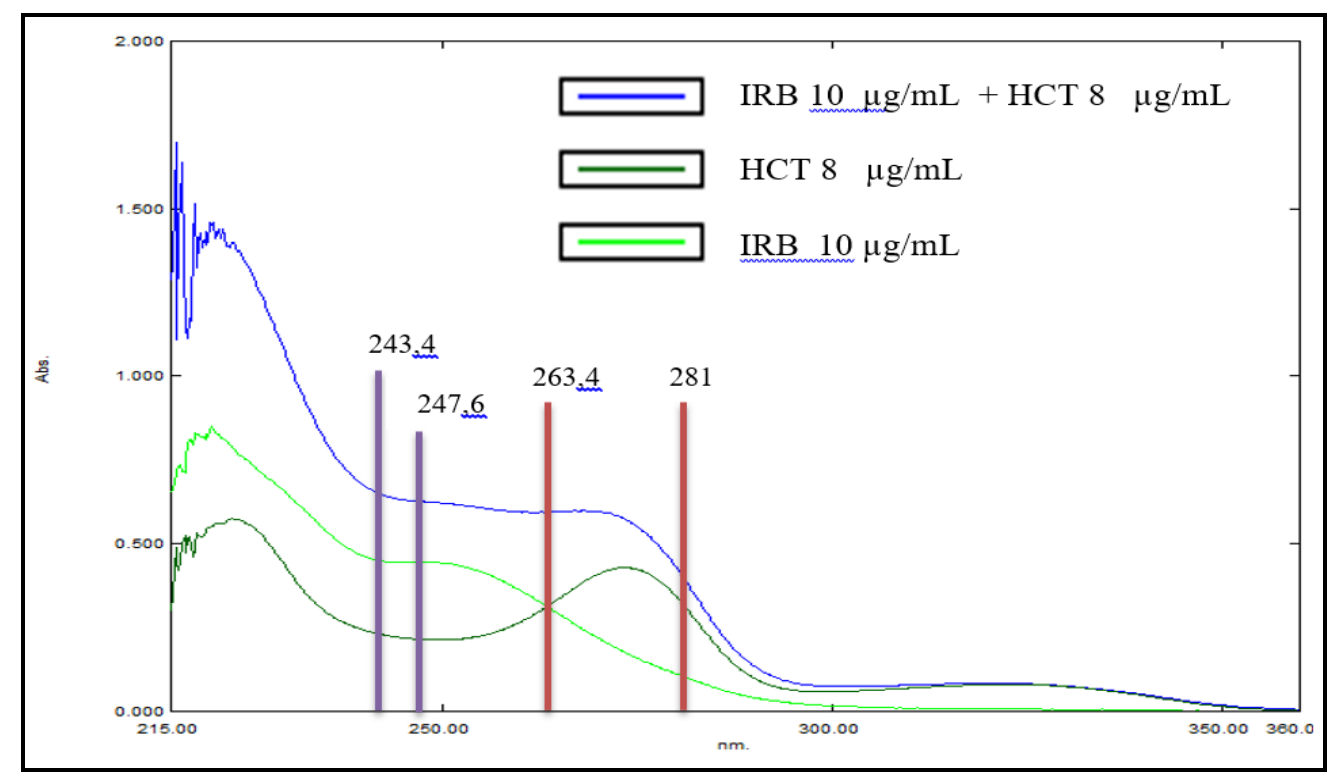

Figure :1 Overlain spectrum of IRB and HCT

Table: 1 Result of calibration readings for IRB and HCT

\begin{tabular}{|l|l|l|l|}
\hline $\begin{array}{l}\text { Concentration } \\
(\mathbf{p p m}) \text { IRB }\end{array}$ & $\begin{array}{l}\text { The difference in absorbance from } \\
\text { HCT at 263.4 and } \mathbf{2 8 1} \mathbf{~ n m}\end{array}$ & $\begin{array}{l}\text { Concentration } \\
\text { (ppm) HCT }\end{array}$ & $\begin{array}{l}\text { The difference in absorbance } \\
\text { from IRB at 243.4 and 247.6 } \mathbf{~ n m}\end{array}$ \\
\hline $\mathbf{5}$ & 0.0934 & 4 & 0.0067 \\
\hline $\mathbf{7 , 5}$ & 0.1483 & 6 & 0.0097 \\
\hline $\mathbf{1 0}$ & 0.2003 & 8 & 0.0130 \\
\hline $\mathbf{1 2 . 5}$ & 0.2545 & 10 & 0.0165 \\
\hline $\mathbf{1 5}$ & 0.3079 & 12 & 0.0191 \\
\hline
\end{tabular}

From the study of overlays, the two wavelength spectrums were chosen for $243.4 \mathrm{~nm}$ and $247.6 \mathrm{~nm}$ IRB where the difference in absorbance was 0 so that it could be used for HCT analysis, whereas for HCT $263.4 \mathrm{~nm}$ and $281 \mathrm{~nm}$ was used for IRB analysis. For the calibration curve, the ratio spectrum ranges from 5-15 $\mu \mathrm{g} / \mathrm{mL}$ (series A) and 4$12 \mu \mathrm{g} / \mathrm{mL}$ for HCT (series B) and the mixture of both drugs (series $C$ ) in the same concentration range with a ratio of 5: 4. The result of calibration reading for IRB and HCT are shown in table 1.

Assay for the commercially available tablet dosage form is performed and the results are shown in table 2 . The results of drug levels in the market indicate that the drug meets the requirements with values in the range for 270$330 \mathrm{mg}$ IRB and 11.25-13.75 for HCT.

\section{Method validation:}

The developed method is validated for linearity, precision, and accuracy.

\section{Linearity}

The calibration curves of IRB and HCT were linear in the range of $5-15 \mu \mathrm{g} / \mathrm{mL}$ and $4-12 \mu \mathrm{g} / \mathrm{mL}$ respectively.

The regression equations of calibration curves were

$\mathrm{Y}_{\mathrm{irb}}=0.0207 \mathrm{X}-0.0047, r=0,9994$ for IRB and

$\mathrm{Y}_{\mathrm{hct}}=0.001606 \mathrm{X}-0.000129, r=0,9995$ for HCT

\section{Precision}

Relative standard deviations (\% R.S.D.) for inter day were found to be 1.15 and 3.33 for IRB and HCT, respectively. The intraday precision showed \% R.S.D 1.72 and 3.91 for IRB and HCT, respectively.

\section{Limit of Detection (LOD) and Limit of Quantitation (LOQ)}

The LOD for IRB and HCT was found to be 0.6374 $\mu \mathrm{g} / \mathrm{mL}$ and $0.4931 \mu \mathrm{g} / \mathrm{mL}$ respectively. The LOQ for IRB and HCT was found to be $1.9314 \mu \mathrm{g} / \mathrm{mL}$ and 1.4943 $\mu \mathrm{g} / \mathrm{mL}$ respectively. The validation results are shown in table 3.

\section{Recovery}

The percentage recoveries of drug from marketed formulation were determined by standard addition of pure drugs at three $(80 \%, 100 \%$, and 120\%) known concentrations and excellent recoveries were obtained at each level. The percentage of recovery for IRBs is three levels, $80 \%, 100 \%$, and $120 \%$ respectively $100.33,101.14$ and 100.29, while for HCT is 101.72, 99.64 and 99.64. The Recovery studies are shown in table 4

Table 2: Results of simultaneous estimation of AT and EZ in the marketed formulation by Dual Wavelength spectrophotometry method

\begin{tabular}{|l|l|l|}
\hline Component & Claim on label (mg) & Content (mg) \\
\hline IRB & $\mathbf{3 0 0}$ & $324,11 \pm 8,09$ \\
\hline HCT & $\mathbf{1 2 . 5}$ & $11,78 \pm 0,56$ \\
\hline
\end{tabular}


Table 3: Optical characteristics of the proposed methods and results of formulation analysis \& precision study

\begin{tabular}{|l|l|l|l|}
\hline No. & Parameter & IRB & HCT \\
\hline $\mathbf{1}$ & $\begin{array}{l}\text { Analytical weve lengths for } \\
\text { determination }(\mathrm{nm})\end{array}$ & $263.4 \mathrm{~nm}$ and 281 nm & 243.4 and 247.5 \\
\hline $\mathbf{2}$ & Lamber beer $(\mu \mathrm{g} / \mathrm{mL})$ & $5-15$ & $4-12$ \\
\hline $\mathbf{3}$ & Regression equation & $Y_{\text {irb }}=0.0207 \mathrm{X}-0.0047$ & $\mathrm{Y}_{\text {hct }}=0.001606 \mathrm{X}-0.000129$ \\
\hline $\mathbf{4}$ & Correlation coefficient & 0,9994 & 0,9995 \\
\hline $\mathbf{5}$ & Accuracy $(\%)$ & 100,59 & 100,34 \\
\hline $\mathbf{6}$ & Precision $(\mathrm{RSD})(\%)$ & 0,87 & 45,70 \\
\hline $\mathbf{7}$ & Interday $(\% \mathrm{RSD})$ & 1.15 & 3.33 \\
\hline $\mathbf{8}$ & Intraday $(\% \mathrm{RSD})$ & 1.72 & 3.91 \\
\hline $\mathbf{9}$ & LOD $(\mu \mathrm{g} / \mathrm{mL})$ & 0,64 & 0,49 \\
\hline $\mathbf{1 0}$ & LOQ $(\mu \mathrm{g} / \mathrm{mL})$ & 1,93 & 1,49 \\
\hline
\end{tabular}

Table 4: Recovery studies

\begin{tabular}{|l|l|l|l|}
\hline No. & Drug & $\begin{array}{l}\text { Concentration } \\
(\boldsymbol{\%})\end{array}$ & $\begin{array}{l}\text { Mean } \\
\text { \% recovery }\end{array}$ \\
\hline $\mathbf{1}$ & IRB & $80 \%$ & 100.33 \\
\hline $\mathbf{2}$ & IRB & $100 \%$ & 101.14 \\
\hline $\mathbf{3}$ & IRB & $120 \%$ & 100.29 \\
\hline $\mathbf{4}$ & HCT & $80 \%$ & 101.72 \\
\hline $\mathbf{5}$ & HCT & $100 \%$ & 99.64 \\
\hline $\mathbf{6}$ & HCT & $120 \%$ & 99.64 \\
\hline
\end{tabular}

\section{CONCLUSION}

The proposed dual wavelength method gives accurate and precise results for determination of irbesartan and

\section{REFERENCES}

1. Moffat AC, Osselton MD, Widdop B. Clarke's Analysis of Drugs and Poisons. 4th ed. London: Pharmaceutical Press; 2011; Page No.73-85.

2. Raskin P, Guthrie R, Flack JM, Reeves RA, Saini R. The long-term antihypertensive activity and tolerability of irbesartan with hydrochlorothiazide. J Hum Hypertension. 1999; (13):683-7.

3. Vahora S, Mehta F, Chhalotiya U, Shah D. Dual Wavelength Spectrophotometric Method for Estimation of Cilnidipine and Telmisartan in Their Combined Dosage Form. Res Rev J Pharm Anal. 2014; 3(2):22-9.

4. Bindaiya S, Bankey S, D.jain. Simultaneous Determination of nitazoxanide and ofloxacine in Tablet Dosage Form by Ultraviolet Spectrophotometry (Dual Wavelength Method). Int J Chem Tech Res. 2010; 1(2):11-5. hydrochlorothiazide in marketed formulation (tablets) without prior separation and is easily applied for routine analysis. The most interesting feature of the dual wavelength method is its simplicity and rapidity. The validation method has been demonstrated by a variety of tests for linearity, accuracy and precision. The proposed methods were successfully applied to the determination of these drugs in commercial tablets.

\section{ACKNOWLEDGEMENT}

The authors are grateful to the National Agency of Drug and Food Control of Republic of Indonesia and PT. Kimia Farma to provide standard IRB and HCT in this study.

5. Pradhan PK, Rajput PN, Kumar N, Joshi B, Upadhyay UM. Simultaneous estimation of Flurbiprofen and Gatifloxacin by dual wavelength UV spectroscopy method in an eye drops. Int J Pharm Sci Rev Res. 2014; 27(2):96-9.

6. Kamal AH, El-malla SF, Hammad SF. A Review on Uv Spectrophotometric Methods for Simultaneous Multicomponent Analysis. Eur J Pharm Med Res. 2016; 3(2):348-60.

7. Harmita. Petunjuk Pelaksanaan Validasi Metode dan Cara Perhitungannya. Maj Ilmu Kefarmasian. 2004; 1(3):117-35.

8. Ermer J, John JH. Method Validation in Pharmaceutical Analysis: A Guide to Best Practice. Weinheim, FRG: Wiley-VCH Verlag $\mathrm{GmbH} \& \mathrm{Co}$. KGaA; 2005. 1-403 p. 